\title{
Researching emotions and the emotions of researching: the strange case of Alexithymia in reflexive research
}

\section{Matthew J. Brannan}

Keele Management School,

Research Institute for Public Policy and Management,

Keele University, UK

E-mail: m.brannan@mngt.keele.ac.uk

\begin{abstract}
Despite the recent 'reflexive turn' in fieldwork-based sociology, and its organisational variants, empirical research often seems to ignore the role of the researcher's emotion in the collection of data and the creation of textual representations. The paper offers a retrospective autoethnographic account to argue that the separation of the physical act of research from its emotional experience is unsustainable. The paper offers a critique of the institutional framework of PhD study, which often seems to perpetuate a certain inattention to issues of emotionality within the research context, and argues the emotional experiences are key fieldwork experiences and an essential part of ethnographic study.
\end{abstract}

Keywords: emotions in research; retrospective/auto-ethnography; reflexivity; ethics.

Reference to this paper should be made as follows: Brannan, M.J. (2011) 'Researching emotions and the emotions of researching: the strange case of Alexithymia in reflexive research', Int. J. Work Organisation and Emotion, Vol.

Biographical notes: Matthew J. Brannan is a Senior Lecturer in Management at Keele Management School, Keele University and Director of International Partnerships. Previously, he held a post at the Centre for Labour Market Studies at the University of Leicester and was awarded a $\mathrm{PhD}$ from Wolverhampton University for his work on Call Centres and Employee Resistance. His current work focuses on the growth of the Service Sector and the contemporary experience of work using Ethnographic Techniques to gain an immersive insight to the world of work. He has written about the use of Role Play in Call Centre Recruitment and Selection processes, the engagement of worker's sexuality in customer service environments, the career path of female junior Managers and Employee Branding.

\section{Introduction}

The road to reflexive practice is paved with good intentions.

(Karl Maton, 2003, p.56) 


\begin{abstract}
I want to suggest it is by the emotions of affect that class struggle is being expressed, although not often heard. These utterances are however an expression of an alternative value system, one not easily recognised, often misrecognised, and certainly one that cannot be framed in the shape of a self that is in any way interested in accruing exchange-value to itself.
\end{abstract}

(Beverley Skeggs, 2004, p.90)

The explosion of interest in, and critical study of, emotion within organisational contexts is widely considered to have begun with the publication of Arlie Hochschild's The Managed Heart (1983). Having energised a desire to identify and understand the nature of emotional labour in paid employment, Hochschild's work provides an example of qualitative study based on observation and interviews (Hochschild, 1983, p.14; Bryman and Bell, 2007, p.409), which clearly involves an emotional encounter between the researcher and the research participant. Spawning wider conceptual and empirical work into studies of emotion in society (Thoits, 1989), organisations (Fineman, 1993, 2000) and the workplace (Bolton, 2004), the study of emotion has very much been driven by qualitative, often ethnographic research. It has been suggested that such styles of research necessarily involve the researcher in "the management of feeling to create a publicly observable facial and bodily display" (Bolton, 2004, p.7) and "dealing with other people's emotions" (James, 1989, p.15). The study of emotions in others is, therefore, clearly an emotional endeavour on a number of levels.

Given the growing interest in the emotions of others, it is, therefore, somewhat surprising that the emotions involved in the research process, and specifically those experienced by the researcher during fieldwork, have not come under more scrutiny (Dickson-Swift et al., 2009). Whilst there are notable exceptions (see, for example, Lumsden (2009)), researchers' emotions are noticeably absent from research accounts and this, therefore, might even be considered an 'alexithymic' tendency, a term borrowed from psychiatry defined as "the inability to find appropriate words to describe [ones] feelings" (Sifneos, 1973, p.255). Such a diagnosis is rendered strange given the emotional sensitivity of a great deal of organisational research to the emotions of others and the growth of reflexive approaches to research. In attempting to account for emotional absence or Alexithymia, Bellas (1999, p.97) notes that research is culturally defined as a 'masculine activity' and hence any element of emotional labour (which has been historically associated with femininity) is 'typically minimised or overlooked'. Indeed in the study of the history of sociology, Laslett (1990, p.429) argues 'cool-rationality' and 'un-feeling knowledge' provided "a cultural space to which men could aspire without threat to their masculinity and provided a gate keeping mechanism that limited women's entry". The marginalisation of emotions from research accounts, therefore, has much to do with the gendered assumptions surrounding the nature of emotional encounters, and research accounts that explicitly include emotional elements are less likely to conform to masculine ideals of what 'counts' as research. This approach, however, has important implications for the practice of research and research outcomes, as Jaggar (1989) argues for example, the construction of emotions as 'epistemologically subversive' is a cultural blind spot in relation to emotions and their importance for the construction of knowledge.

Yet, the systematic marginalisation of emotions from research accounts seems at odds with wider trends toward a 'reflexive movement' (Holland 1999, p.482) in social research, where researchers seek to acknowledge their active role in co-construction of data and their impact on field relations. Etymologically deriving from the notion of 
'bending back', from the perspective of social research, reflexivity means to bend knowledge back on itself, or as Pillow suggests

"To be reflexive, ... not only contributes to producing knowledge that aids in understanding and gaining insight into the workings of our social world but also provides insight on how this knowledge is produced." (Pillow, 2003, p.178)

Attention paid to the conditions of production of knowledge leads to a wide range of practices, but as Hardy et al. note has led to a particular focus on

"the relationship between the research and the research subject ... and particularly the limitation of research in representing the subjects under study and their effect on the creation of 'knowledge'." (Hardy et al., 2001, p.532)

Given a context of increasing awareness of the importance of acknowledging the conditions in which accounts are produced, it is hard to comprehend the absence of systematic accounts of the way in which emotions in research play a key role in shaping research accounts. Indeed, a fully reflexive account of the research process would surely acknowledge the importance of emotional dynamics in understanding the relationship between the researched and the researcher.

In contrast to accounts that marginalise emotions, the contribution made here is to explore the process of fieldwork as an 'emotional encounter' through the description of emotional interactions between the researcher and research participants. Having described the emotional terrain upon which this research was conducted, the paper then seeks to explore the impact of emotional encounters upon the research process. The paper is organised as follows: first, the paper starts by exploring recent developments in the understanding of empirical social research, which position reflexivity at the heart of the research relationship. This location is argued to be important because it suggests a sensitivity to the dynamics of the research relationship and renders problematic crude versions of empiricism, which take the 'collection of data' as unproblematic processes. Furthermore, reflexivity calls for more attention to be paid to how researchers are implicated in various ways in the accounts that they produce. The original research aims and their relation to the concept of emotional labour are, therefore, established. The paper then argues that this research, and indeed, most qualitative research efforts are inherently 'emotionally intensive' activities. Leading on from this, the paper considers the specific process of negotiating access and gaining entry to the field and the establishment and development of relations with participants as a nexus that clearly involves emotional dimensions and interactions between participant and researcher. The process of building relations with research participants is explored together with the practical issues of conducting research whilst physically working in the research environment. The paper concludes with a consideration how this might be usefully related to our understanding of fieldwork processes and the nature of conducting research within the institutional context of higher education.

\subsection{The reflexive turn and emotional absence}

The reflexive turn in empirical fieldwork is argued to amount to calls for researchers to pay more attention to their role in the shaping of the empirical data that they collect. It 
"involves a shift in our understanding of data collection from something objective that is accomplished through detached scrutiny of "what I know and how I know it", to recognising how we actively construct our knowledge." (Finlay, 2002, p.532)

Indeed, it could be argued that reflexivity makes the notion that anything is 'collected at all' problematic; or put another way,

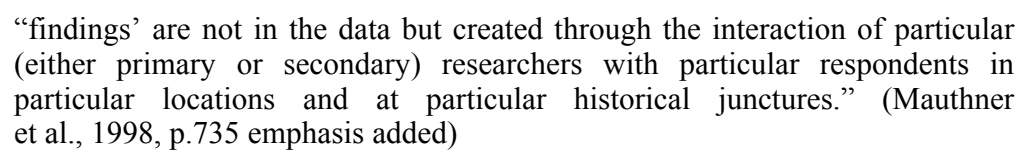

Alvesson (2003, p.14) suggests that reflexivity offers researchers two things: first, it removes the overly simplistic notion of the possibility that 'data reveals reality' and second fosters a sensitivity to 'meaning' within the research process. Reflexive sensitivities, therefore, work to disrupt crude empirical notions that data can ever 'reveal' reality or the equally crude view that data can simply be read from participants. Suggestive of a move from the discussion of the hard concrete 'facts' to softer transient 'meanings' also, in many ways, seems to say something profound about the appropriateness of various instruments for research. If, for example, the object of research becomes something as ephemeral as 'meaning' how can researchers ever know their explanations 'capture' these meanings adequately? Questions of validity and reliability, more normally associated with more quantitative approaches, therefore still remain pertinent and important (Hertz, 1996; Creswell and Miller, 2000).

Lynch (2000) provides an open inventory of reflexivities and this points to the variants and possibilities related to reflexive practice. Whilst this scope of practice is important, we might consider reflexivity to have two broad elements; epistemology reflexivity, which focuses on the impact of researchers' theories of knowledge, assumptions about the world and the impact that these have upon the data collected, and personal reflexivity, which involves an analysis of the research process and understanding of how the specific design and conduct of the research influences the kinds of data produced (Willig, 2001). In both of these domains, the noted absence of concerns and discussion in relation to researchers' emotions is problematic. It seems odd that personal reflexivity would exclude material that has an emotional component. What else could be more personal, yet have such an impact on how researcher comes to think about fieldwork observations and corresponding construction of data, for example?

Yet, reflexivity is not without its critiques and is far from a panacea for research practice. Critics of reflexivity, for example, argue that attention to researchers' emotions amounts to self-indulgence especially where areas of genuine research interest are forgone in favour of an egotistic focus on the researcher (Coffey, 1999). Similarly a reading of Chia suggests that researchers may invoke reflexivity as a strategy to authenticate their own research without turning reflexively back on themselves; so called first order reflectivity (1996, p.44). Whilst it is almost certainly true that forms of reflexivity are deployed as capital to invest authority in the production of ethnographic texts, Brewer's (1994) argument locates reflexivity as key to a reconstruction of ethnographic authority. Alternatively, reflexivity might assume the status of a virtue and, therefore, become a key marker of distinction and capital to be leveraged in the battle between resources and status within the academic field (Lynch, 2000). Against this critique, Alvesson offers 
Pragmatic Reflexivity (2003), which might be considered to work to balance "endless reflexivity and radical scepticism with a sense of direction and accomplishment" (p.14).

This paper starts from the observation that emotional accounts of research are seldom to be found in academic work and in the context of the recent 'reflexive turn' in fieldwork-based sociology; this is an artificial and unsustainable position. Empirical research often seems to ignore the role of the researchers' emotions in the field-led research, collection of data and the creation of textual representations. This paper now presents an autoethnographic account to seek to provide a number of emotional vignettes drawn from extended ethnographic fieldwork to demonstrate how initial emotional responses act almost as an arc impulses with little time given to reflection or a more sustained level of reflexivity in the field and wider research processes.

\section{The case study context}

Workplace ethnographies arguably provide not only a well-suited research methodology for attempting to comprehend the contemporary experience of work (Brannan et al., 2007) but also a potentially rich and hitherto untapped source of insights into the emotional dimensions of fieldwork. Whilst such methods are well used within the field of industrial sociology, their implementation is far from unproblematic. To conduct ethnographic research, I secured employment at CallCentreCo. between completing a Master's Degree and starting a PhD, during the summer of 1999. I was employed full time at the case study call centre for a period of 13 months and engaged in all duties as required of a call centre employee. At the same time as learning the job of a Customer Service Representative (CSR) and working full time at the call centre, I also started and maintained PhD study. I was, therefore, a full participant in the research setting in the fullest sense (Gold, 1958).

The fieldwork upon which this paper is based was designed to explore issues surrounding the contemporary experience of work and employment. The context of telephone call centres was chosen as an archetypal form of interactive-based service work. Specifically, the research sought to explore the ways in which competing quality and quantity imperatives, as documented in the existing call centre literature (see, for example, Taylor and Bain (1999) and Taylor et al. (2002)), are managed by a small team of CSRs.

Emotional interactions lie at the very heart of CSRs work routine. Taylor and Bain (1999, p.103), for example, suggest that it is 'evident' that call centre work involves the performance of emotional labour, and key to this is an understanding of the relationship of the CSRs with customers who often require a range of emotional responses and managers increasingly utilising forms of neo-normative control (Fleming and Sturdy, 2011). Moreover, the specific nature of these emotional responses is of huge importance to organisations. Taylor, in making sense of this, links the mobilisation of emotional labour with the pursuit of surplus value. In doing so, draws attention to the logic of valorisation, itself inextricably linked into the concept of emotional labour:

"Emotional labour can be defined [as] feeling management which is performed as part of paid work, serving the interests of the employers in maximising surplus value." (Taylor, 1998, p.85) 
The ascendancy of call centre employees as the product (Macdonald and Sirianni, 1996; Sturdy et al., 2001, p.5) has profound effects and Ashforth and Humphrey (1993, p.90), for example, define emotional labour in service work as being about displaying 'appropriate' emotions. In many call centre environments, emotional performances are so significant that often the processes through which such interactions are enacted are carefully and systematically regulated (Brannan and Priola, 2011).

Having located the paper within the development of reflexive social research and situated the emotional focus and context of the research, the paper now seeks to explore some of the emotional encounters that occurred during the pursuit of fieldwork. The purpose of this is to highlight the impact that such emotional encounters play within the research relationship and upon data collection and analysis. This will then provide the foundation for a conceptual discussion of the role of emotions in pursuit of fieldwork.

\section{Understanding managerial misunderstanding}

Full participation in the research setting offers a number of obvious benefits and some authors writing on the experience of Ethnographic research remark upon how the researcher must inhabit two worlds (Sherif, 2001). These might be termed the 'field-world' and the researcher's normal 'everyday world'; the acknowledgement of the separations of these worlds, however, is automatically to acknowledge the distinction between the two and the work of negotiation that must take place to situate the researcher in either or both, a task that is made more complex by issues of temporality. Reflecting upon my fieldwork, it is apparent to me how, throughout the fieldwork, I attempted to keep these worlds as separate as possible. I was reluctant, for example, to discuss my academic background and interests (wider than the research focus and background required for ethical disclosure) during work at the call centre, whilst at the same time being hesitant to talk about my experience of being a CSR outside of the call centre. Despite this artificial separation, on occasion these two separate worlds inevitably collided and eventually blurred (Leibing and Mclean, 2007). One example of such a collision was the formal institutionalised bureaucracy of conducting research as a $\mathrm{PhD}$ student and, in particular, the University's Ethics committee and its requirement that all fieldwork be submitted for scrutiny to an ethics review board as part of the annual review process. This required a double disclosure; first, to the ethics committee, thus allowing the academic world remote access to the field world and, second, discussing my research with call centre staff, thus allowing access to the academic world from the field.

Whilst all organisational research raises ethical issues for the researcher and potential dangers for the researched, ethnographic investigation poses particular challenges and ones that are not readily solved by conventional approaches to ethical research (Bosk, 2004). Workplace ethnographies require the construction of an asymmetrical relationship where the researcher's primary aim, and reason for being in the environment, is to conduct sociological enquiry. This aim is, of course, divergent from other participants in the field and is operationalised by becoming a participant within the workplace. Following Murphy and Dingwall (2001), principles to guide ethnographic research can usefully be derived from notions of 
- non-maleficence and beneficence

- autonomy and self-determination for research participants

- justice.

The maintenance of an ethical climate for the investigation was fostered through a discussion of the research, its interests and what the concept of 'data' might mean in an everyday call centre. This discussion took place with fellow team members and call centre managers and explanations were given about the mode of data collection and how the data would be stored and used and this included assurances regarding anonymity. The possible dangers or potential harm caused by ethnographic research for participants were explored, and issues such as embarrassment, fear and uncertainty were discussed on a one-to-one basis.

Despite the desire to seek informed consent, the duration of the research meant that the establishment of my status as a researcher on entrance to the field might have become blurred over the course of the fieldwork. Indeed, much ethnographic research is predicated upon this process of 'naturalisation', the idea that researchers' initial 'strangeness' in-situ will become eroded over time. Whilst it is not possible to know how all team members and managers constructed my role in the field, views were reconfirmed spontaneously on many occasions through open discussion with team members. For example, a colleague might raise particular questions in connection with the research, or would remark on aspects of the research agenda. Furthermore, on occasions when informal discussions touched upon areas of specific research interest, the opportunity to remind the participants of the research agenda was taken and permission sought to make a note of the conversation. Finally, my status as a researcher was reconfirmed by re-entry into the field to conduct follow-up interviews. It was highly unusual for employees who had left the call centre to return and therefore my return, this time armed with a tape-recorder and a notebook, was a clear indication of the continuation of the research project.

As part of my initial introduction to the call centre, I had discussed with Amanda (the call centre manager) the possibility of conducting research within the call centre. Outlining a research interest in employee misbehaviour and monitoring, I also had discussions with peer employees that emphasised my interest in their daily routine. The construction of my 'frames of reference' were reflective of my pre-existing concerns to understand the lived experience of CSRs rather than a specific focus upon workplace resistance, which, given the managerial consent that accompanied the project, might have been interpreted as an official investigation of CSR misbehaviour. Despite the candour with which I believed I had articulated my interests, the research intent, especially at managerial levels, was constantly misinterpreted as being concerned with exploring the development of team working. This was indicated in informal discussions with various managers who openly discussed the project but framed the issues in relation to individual participation in teams and team working. Despite specifically highlighting my interest in workplace misbehaviour, the research was constantly misunderstood. As the following example from some seven months into the research demonstrates:

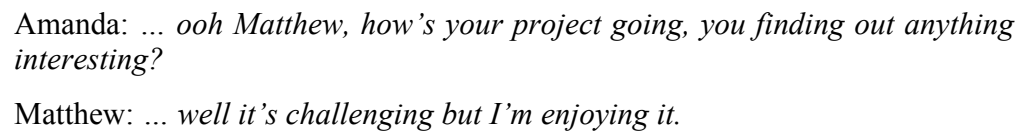




\begin{abstract}
Amanda: ... I read this article I think you'd be interested in it, it's about sharing knowledge in teams, and how software like 'Whiteboard' (a recent addition to the computers in the Call Centre) can help, I thought it would be right up your street?

Matthew: ... Yes in the company magazine ... it's interesting ... I read that, but you know that the project isn't really about knowledge management ... it's more about workplace behaviour and new forms of working.
\end{abstract}

Amanda: ... yeah, but it's all the same thing really isn't it?

(Discussion with Call Centre Manager in staff kitchen, recorded in notebook, later transcribed in fieldwork journal)

Amanda's assertion that "it's all the same thing really" demonstrates an ambivalence to the project, my particular concerns and an example of a misunderstanding, which is analytically significant, as Davies explains

"The development of multifaceted relationships with some individuals in the field helps to sensitise ethnographers to the possibilities not simply for deliberate deception, but for mutual misunderstandings arising from cultural and sometimes personal differences. These latter may be among the most informative for analysis, particularly when the ethnographer and informants manage to uncover and move beyond them." (Davies, 1999, p.83)

I had expected to meet stiff resistance to research, but I sensed a tolerance in terms of what I wanted to do, or perhaps indifference. Although not actively encouraged, I was given clear instructions that I could carry on with my research as long as it did not interfere with any aspect of my work, in particular any research should not impinge upon my time 'taking calls'! Managerial consent was somewhat surprising as, at the time (July 1999-August 2000), a number of high-profile stories of poor conditions in call centres had broken in the national news media and reflecting on this I noted a sense that managers were keen to "reveal another side of call centre work" (informal discussion with call centre manager), and from this perspective, a researcher working as a CSR might be considered as a useful vehicle for a managerial public relations agenda. This highlights the potential for research participants to make use of, or attempt to make use of research for their own ends. Indeed, managerial consent to this project presented further challenges, as I was concerned that my interest in misbehaviour together with managerial approval might lead some CSRs to conclude that I was a management spy.

Reflecting on this central misunderstanding that now seems so apparent, it is clear to me that, as a researcher, the confusion surrounding my research was largely ignored. Feeling irritated that what I considered to be a straightforward research idea could be so misunderstood, my attempts to explain the research further were abandoned as I began to question the legitimacy and usefulness of the project that I was undertaking. Perhaps the research design was at fault? Maybe the research questions were mis-specified? Making sense of this contextually, I felt at the time that I was engaged in an intellectual struggle to define my research, specifically in relation to the literature and a particular historical approach to Industrial Sociology. Such a clear misunderstanding of my research intent made me feel threatened and vulnerable. After all, if I was unable to articulate my research to Management, how was I ever going to satisfy a seemingly hostile academic community? Over time, it has become more apparent that this struggle for identity clearly influenced how I sought to manage field relations. Yet, a more prominent emotion came to dominate, that of fear, or the horror of having access terminated. This, perhaps more 
than any other influence, meant that misunderstandings were not corrected, yet as a number of authors note, this ignoring of emotions is itself a form of emotion work (Reger, 2001).

Perhaps more importantly, so noted by Davis earlier, misunderstandings are analytically important and in fact a rich source of analytical data. This particular misunderstanding displays the cultural difference between myself as a researcher and myself as a call centre worker; the concept of a researcher clearly is an anathema to the call centre, to the extent that it hardly registers. The ambivalence of call centre manager speaks to the value and perception of academic work within the workplace. Tolerated as a curiosity, an eccentricity, perhaps, not facing openly hostility but certainly treated with scepticism. The interaction also reaffirms the primacy of 'answering calls' to all other forms of activity within the domain of the call centre; the crude calculus of capital revealed from beneath the thinly veiled rhetoric of 'teamwork'.

\section{Sarcasm on the shop floor}

In common with other CSRs, I was employed at CallCentreCo. in a standard shift pattern, which lasted from 8.30 in the morning until 5.30 in the evening. Ethnographic observations were recorded in an extensive fieldwork journal, which took the form of a Microsoft Word document, accessed and updated via my desktop computer during quiet periods of the working day. As CSRs were frequently required to use Microsoft Word, I was able to record entries without attracting unwanted attention. In pursuit of the fieldwork, I also participated in a number of social events and voluntary community work, which CallCentreCo. organised and in which all members of staff were encouraged to participate. Observations from these events were recorded in a notebook and added to the fieldwork journal at a later time.

After I had completed my initial induction period and I had been assigned to the NewsCo. team, it became necessary to inform the members of the team about the research. Initially, the team members, like call centre managers, took little interest; the subject was not discussed in any depth although I was aware that there were a number of issues about which the CSRs in the NewsCo. team were concerned. Occasionally within the first month of employment, I would be asked "what is it that you're doing again?" (Question from unknown team member, response not recorded). In contrast to the ambivalence of Management, I noted the subject of worker resistance was raised spontaneously a number of times within the team, the following example is notable in particular:

Venkat: (directed to Jenny) arrr, I'm telling Tina (sarcastically) you're late...

Matthew did you get that? Jenny is seven minutes late from lunch, quick write

that down! (Group laughter)

(Observed team interaction, recorded in fieldwork journal)

The interaction demonstrates how despite plans, preparations and research design, the flux of fieldwork is clearly hugely influenced by emotional responses to events, conversations and observations in the field. Despite having what I considered to be a clear research agenda, I felt embarrassed and undermined by Venkat's comments, the whole research endeavour rendered rather silly and inconsequential by this clever and 'knowing' comment. Such sentiments and expressions of distain from the shop floor were 
not uncommon and as a direct emotional response I began to adopt a more 'covert' approach in the sense of attempting to keep a lower profile than originally intended. The attempt at humour by Venkat shows a veiled awareness of the issues of interest within the research and also signals to the rest of the group that caution is required. Suspecting that the knowledge of my research agenda, in particular the focus on workplace resistance, had impacted upon the behaviour of the CSRs in the team, I decided not to openly initiate a discussion based on themes of resistance within the team. Instead, I would allow the subject to arise in discussion from within the group and then ask questions to explore issues further if appropriate.

If anything, the veil of credibility surrounding my research that endorsement by the call centre managers had given the project prevented initial access to areas of workplace misbehaviour. I suspected that my new colleagues were wary of my agenda and hence were reluctant to discuss resistant practices openly.

\section{$5 \quad$ Taking sides?}

To become an active member of any team within the call centre, all new recruits were required to complete a period of training, which would notionally last for around four weeks. The training consisted of two elements. First, structured technical training was provided centrally within the call centre; this aimed to ensure that all new recruits were given the generic technical skills needed within the call centre to be able to operate the various systems and procedures such as the telephone system and the computer database. Second, more specific client training was provided in a decentralised fashion and this training took place essentially within the team structure whilst 'live' on the phones.

Although many trainees expressed concerns about the degree to which they felt confident about the prospect of their ability to deal with the work as set out in procedures, very few CSRs reported problems learning how to operate the systems to the trainers. Despite having previous computing experience, and of working in customer services, I found the need to use the computer at the same time as talking on the phone a demanding task. I also noted that the responses to the difficulty of training were distinctly gendered. Trainers often adopted a caring disposition to female CSRs and male CSRs who experienced difficulties seemed to adopt a more aggressive attitude reflecting the trainers who adopted a more 'macho' style when dealing with questions from male CSRs:

Matthew: ... Marc, did you get all that?

Marc: ... you must be joking.... all that (database) shit goes straight over my head.

Matthew: ... yeah I know what you mean, it's difficult to take it all in, I find it very confusing...

Marc: ... I'll just talk to them anyway (interrupted)

Matthew: ... what do you mean, 'talk to them', you mean the client?

Marc: ... yeah you know ... to buy yourself more time, keep them, y'know ... talking, that'll give me more time.

(One-to-one discussion during training session, recorded in notebook edited and transferred to fieldwork journal)

Matthew: ... you know what Lisa, I really don't think I'm getting this at all. 
Liz: ... (laughing) I know, I was talking to the other Liz from the TrainCo. desk and she said you never really get to know everything, like what to do in all situations, I think a lot of 'em just make it up.

Matthew: ... I guess so...

Liz: ... that's ok as long as you can get away with it though, I don't think I can, it worries me, what's it going to be like and all that. I'm dreading doin' it for real.

(One-to-one discussion during training session, recorded in notebook, edited and transferred to fieldwork journal)

My fears and trepidation regarding being able to perform the job role were very real, as the above-mentioned quotes indicate I took the opportunity to discuss my fears with other CSRs. Korczynski (2003) notes how customer service workers turn to each other to cope with the emotional stress of the job role, and in relation to this, a key concern for the trainees seemed to be the potential for having to deal with what was termed 'awkward' customers or clients. A number of stories had begun to circulate amongst the trainees about customer interactions that had included verbal abuse. Despite the clear angst of a number of the trainees on this issue, the trainers seemed unwilling or unable to discuss possible strategies in response to such calls.

Helen: ... I just wanted to ask what we should do if we get an awkward one? (Referring to a potential abusive client)

Trainer: ... well, you should just try and be as helpful as possible, you know like get all the information you need and end the call as quickly as you can

Jim: ...I've heard that sometimes you get an earful, is that right?

Trainer: ... well sometime people get upset, but it's not personal, don't let it affect you, just do your job.

(CSR and trainer interaction, observed during training session, recorded in notebook and later transferred to fieldwork journal)

As a counter to the lack of clear support from trainers, the trainees resolved to offer support to each other if such circumstances arose. The following discussion took place away from the training room on a coffee break with most of the trainees present.

Jim: ... I don't really think it's right that we should be expected to take calls if we're getting abuse.

Nicky: ... I don't think it's like that really, I mean when we start like, I've worked in other call centres and there is no way you'd have to put up with things like that, I think as long as the staff stick together we'll be ok ... I don't think they (referring to the trainers) really know what it's like on the desks.

Through informal discussions with colleagues, I was able to ascertain that generally the initial period of employment within the call centre is considered the most demanding. I was told that often it was 'touch and go' (General discussion with Tina, recorded in fieldwork journal) as to whether new recruits would make it through their initial training period. In some respects, this seems to explain why little attempt is generally made by established staff to get to know temporary staff. Furthermore, I learnt that whilst other call centres were not considered as 'tough' in terms of becoming proficient, high turnover especially of new staff was common. I was able to discuss the transition from training to work with the call centre manager: 


\author{
Matthew: ... it seems that the transition from training to working can be really \\ stressful. \\ Amanda: ... yeah I know, it is difficult to get the balance right but I do think \\ that you really need to be a certain 'kind' of person to do the job well, you have \\ to be fairly tough. \\ Matthew: ... To deal with difficult calls? \\ Amanda: ... That's one aspect of the job, but it's better if staff find out early \\ that the service centre is not for them, rather than later.
}

The response from the call centre manager illustrates how the transition from training to working within the CallCentreCo. Call centre effectively constitutes a continuing recruitment process. The initial 'shock' of being thrust into taking calls in the call centre can be somewhat overwhelming, and it appears that the call centre managers use this as a method for assessing the strength of new employees. Little is done to mitigate the stressfulness of this situation by the call centre management team.

Although, like Liz, I contemplated withdrawing from the call centre, I felt great support from my colleagues within the team. Although Liz reported that she also felt this support, I was constantly encouraged and my mistakes and errors were supported by other team members who constantly reassured me that the situation would improve as I became more proficient and experienced; this reassurance was vitally important. The constant repetition and reinforcement of the daily call centre routine did mean that, like other new recruits, I was able to come to terms with the daily demands of working in the call centre. Although, even after a year of working on the same team, I never really felt totally proficient and the 'randomness' of the calls at times meant that I felt unsure about the correct procedures to follow. I suspect that this was the same for many CSRs.

The limited nature of the training and the way in which new recruits were left to sink or swim made me feel hostile to many of the call centre managers. It also promoted a number of issues with respect to my role in the field. At the same time as the fieldwork was taking place, the Trades Union Congress (TUC) was running a high-profile campaign to recruit call centre workers. I was aware that CallCentreCo. did not have a recognised trade union and that the 'it's your call' campaign might be the perfect opportunity to establish one. Yet, despite this opportunity I felt frozen into inaction, too concerned with maintaining my low profile. However, despite this dilemma and a sense of shame owing to my inaction, I did engage in a number of more 'subversive' activities, in which I sought to encourage those around me to reflect on the logic of the call centre and its organisation.

Within the call centre, the Automatic Call Distribution (ACD) software plays the role equivalent to the production line within a factory (Russell, 2002) and significantly is, therefore, a key way in which the relationship between Capital and Labour is managed. The effective dehumanisation of the control of the Labour process thought technological apparatus effectively reduced tensions between CSRs and managers within the call centre and presented little scope or opportunity for CSRs to subvert the mechanics of the productive process. Pressure to answer calls as quickly as possible was exerted, not only by supervisors and problem managers, but also from other CSRs within the team. The unwritten rule within the call centre was that a ringing phone had to be answered and indeed the expectation was often that this would be achieved before the second ring. Yet the asking of the question, and thus questioning of rule, therefore, 
become provocative and political act and prompted some CSRs to reflect upon some of the unquestioned assumptions of the daily life of the call centre:

Venkat: ... There is no reason not to answer calls quickly, I mean if a call comes through you must be on 'ready' status, that's what it means, you're ready! All you have to do is press a button and you're connected, you shouldn't really hear the phone ring to be honest, it should just be 'bang', call coming through and it's answered and you're away.

(One-to-one discussion with Problem Manager, during team-based training, recorded in fieldwork journal)

Matthew: ... Do you ever think like, 'sod it', I'm not answering this one?

Jenny: ... You can't do that, not here!

Matthew: ... What are you talking about? Of course you can, you just don't answer it!

Jenny: ...oh yeah (laughing) what happens then, it's like ringing and ringing and you're sitting there with your arms folded.

Matthew: ... Well you just wait for it to go away, like a missed call.

Jenny: ... A missed call, that's really bad, it means that NewsCo. have tried to contact us and they couldn't get through, the whole thing would fall down, why would you pay for a service that you can't use? ... And besides, listen (motions to the rest of the Call Centre) can you hear phones ringing and ringing?

Matthew: ... No, that's my point, all these phones and not much ringing there're all answered straight away.

Jenny: ... That's MY point, it would be totally out of character, it's just not what we do! (derisory shake of the head).

(General discussion in quite period, recorded in fieldwork journal)

As outlined earlier, the technological character of ACD within this call centre provided an effective shroud to the actual Labour processes involved, with CSRs seemingly assuming that the process was both inevitable and equitable. Moreover, on occasion, agents would express frustration against the structural arrangements of the call centre and this would often be directed towards the ACD system. I witnessed the following expression of frustration vented towards the system:

Rajesh: [finishing a call] ... yeah o.k., don't worry we'll get onto it right away, I'll get back ... yeah I'll call you later... [terminates call by selecting 'end call' ] ... [phone immediately rings again whilst Rajesh is still entering data regarding previous call] ... fuckin' 'ell, give me a chance... (Phone continues to ring)

Venkat: ... should 'ave gone in wrap-up, use your wrap-up! ... (Phone continues to ring)

Rajesh: ...fuckin' piece of shite...[bangs dial/answer button on phone unit with fist] ... [reverts to composure] ... Good afternoon NewsCo. Service desk, Rajesh speaking, how can I help you?

(Observed customer/colleague interaction during busy period, recorded in fieldwork journal) 
These leading questions constitute guilty academic pleasures; they involve provoking respondents' reflections on their own practice and are intentionally disruptive. Politically, they move the ethnographer beyond being 'sympathetic storyteller' (Foley, 2002, p.470) towards a potential source of instability and change within the working environment. They evoked a sense of pleasure at being able to question the assumptions of the call centre by encouraging my co-workers to do the same. These instances of subversion also carried with them, for me, a sense of guilt at not overtly calling for change, and provide a further clear affirmation of the idea of the researcher as emotional labourer (Jarzabkowski, 2001). This emotional encounter also highlights the in-built emotional tension in ethnographic work, residing in the traditional bias in ethnographic research towards non-interference, or minimising the role of the researcher in the field. In the examples provided here, this led to an emotional conflict where deep fieldwork produced empathy and a sense of responsibility to those that I was researching. In this example, the conflict is played out between raising what might be considered the political aspirations of those I worked with, and those traditional biases that are built upon the assumption of a researcher removed from, but participating in the everyday life of those in the field.

\section{Discussion and conclusion}

In this final section, I seek to draw out the implications of the examples provided earlier and offer an analysis of the complexity of understanding and documenting the emotions of the research process.

This paper provides a number of examples of what might be termed the unintended consequences of research activity. The example of how the intentions of the research were misunderstood by both the call centre manager and the peer employees work to question the assumption that disclosure of research intent can ever be equated to a claim that participants understand fully the nature of the research. Whilst this will hardly come as a surprise to those of a social constructivist persuasion; it does question the continued dominance of approaches to research ethics that are soely based on initial disclosure. Moreover, this example of confusion effectively shielded the true intent of the research and although the account documents how misconceptions were challenged, this confusion certainly seems to have been productive in facilitating ethnographic research. These misunderstandings are clearly therefore grist to the ethnographer's mill, unintended but highly valuable consequences that further underline the iterative nature of the research process.

On reflection, it seems clear how I attempted to separate the fieldwork world from the rest of my life as a PhD student. The moments of overlap between these worlds, such as my attempts to engage with ethical considerations, show how precarious this artificial divide is. This further underlines the point made by Sin (2005) that researchers who engage in extended forms of research cannot rely upon an initial disclosure to assuage ethical concerns over fieldwork. Rather opportunities to restate the researcher's intent throughout the research need to be taken. Feminist scholars have long criticised the distinction between rational and emotional forms of knowing (see, for example, Hubbard et al., 2001; Reger, 2001) in the sense that traditional approaches to social science favour the former. In ethnographic research, despite its extensive links with feminist and 
outsider epistemologies, the rational/objectivist current remains strong. Whilst the omission of explicit consideration of the emotions of conducting research is a form of privileging the rational over the emotional, a rearticulation of the Cartesian mind-body dualism (Foley, 2002), this paper demonstrates that it has also gravely impacted on the ways in which research is carried out, and how data is perceived, recorded and analysed. So in my own account, the misunderstanding of the research by call centre managers is ignored as an interesting and potentially revealing statement on the perception of call centre workers' misbehaviour. Furthermore, my irritation and embarrassment caused by co-workers' jokes about my research and the implication this has for how workers think about their own workplace misbehaviour becomes secondary to my own sense of purpose and confidence in my research design.

This raises the possibility and importance of identifying a corrective for the alexithymic tendency in research. It is clear from the forgoing analysis that it is a mistake to understand emotions simply as attributive to individuals or their actions and therefore it might be more fruitful to consider emotions as a property of social relationships (Emirbayer and Goldberg, 2005) rather than existing within an intra-personal domain. From this perspective, we might move to consider the social context of emotional engagement and interactions and this may provide a way to explore the full analytical importance of emotional responses as indexical to social relations and the logic of the social fields in which they are embedded and from which they emerge. One of the key challenges of this, however, is to move beyond understanding emotions as a property of individual relations, a difficult task when it is considered that much academic work, which claims to be reflexive, is predicated on individualised accounts of emotional interaction. Maton (2003), for example, argues that what passes for reflexivity is mostly sociological, individual and narcissistic. In contrast, and drawing on Bourdieu, he calls for reflexivity that is epistemological, collective, and objective and in this sense the development of wider communities of researchers might open up spaces for an ongoing discussion of the social significance of emotional interactions in a way that is currently unavailable to many researchers beyond seminars and conference events. Similarly, Riach (2009) calls for 'reflexivity-in-practice' as a way of the positioning the participants within an ethical research process. Recognising the role that all participants in the research process may play in the development of 'reflexive-spaces' (Maton, 2003, p.366). Such a collective response to these emotional dilemmas seems entirely in keeping with Brewer's (1994) argument for example that at heart reflexivity has a key role to play in the ascription of authority in research accounts.

Moreover, the researcher is always part of a wider academic community of practice, and it is this community of practice which exerts a greater influence over the way in which research is designed and undertaken, and provides its socialisation and learnt emotional vocabularies (Thoits, 1989, p.319) with which we engage in social research. The inextricable link for many young career researchers between demonstrating competence and intellectual rigour, and their conduct in the field, means that the researcher's emotions, which are seen as an unwanted consequence of fieldwork interactions, may well continue to be marginalised without a more careful and systematically designed social organisation of research practice. 


\section{Acknowledgements}

I thank the Ethnography Symposium held at Liverpool, The ESRC Seminar Series; Emotion and Embodiment (RES-451-26-0428) and Stephanie Russell for constructive discussions about ideas raised in this paper. I also thank the Guest Editors of this journal and the anonymous reviewers of the paper for their significant engagements with its themes.

\section{References}

Alvesson, M. (2003) 'Beyond neo-positivists, romantics, and localists: a reflexive approach to interviews in organizational research', Academy of Management Review, Vol. 28, No. 1, pp.13-33.

Ashforth, B.E. and Humphrey, R.H. (1993) 'Emotional labour in service roles: the influence of identity', Academy of Management Review, Vol. 18, No. 1, pp.88-115.

Bellas, M.L. (1999) 'Emotional labor in academia: the case of professors', The Annals of the American Academy of Political and Social Science, Vol. 561, No. 1, pp.96-110.

Bolton, C. (2004) 'A simple matter of control? NHS hospital nurses and new management', Journal of Management Studies, Vol. 41, No. 2, pp.317-333.

Bosk, C.L. (2004) 'Bureaucracies of mass deception: institutional review boards and the ethics of ethnographic research', The Annals of the American Academy of Political and Social Science, Vol. 595, No. 1, pp.249-263.

Brannan, M.J. and Priola, V. (2011) 'Girls who do boys like they're girls? Exploring the role of gender in the junior management of contemporary service work', Gender Work and Organization.

Brannan, M.J., Pearson, G., Worthington, F. (2007) 'Ethnographies of work and the work of ethnography', Ethnography, Vol. 8, No. 4, pp.395-402.

Brewer, J.D. (1994) 'The ethnographic critique of ethnography: sectarianism in the RUC', Sociology, Vol. 43, No. 3, pp.231-244.

Bryman, A. and Bell, E. (2007) Business Research Methods, Oxford University Press, Oxford.

Coffey, A. (1999) The Ethnographic Self, Sage, London.

Creswell, J.W. and Miller, D.L. (2000) 'Determining validity in qualitative inquiry', Theory Into Practice, Vol. 39, No. 3, pp.125-130.

Davies, C.A. (1999) Reflexive Ethnography a Guide to Researching Selves and Others, Routledge, London.

Dickson-Swift, V., James, E., Kippen, S. and Liamputtong. P. (2009) 'Researching sensitive topics: qualitative research as emotion work', Qualitative Research, Vol. 9, No. 1, pp.61-79.

Emirbayer, M. and Goldberg, C.A. (2005) 'Pragmatism, bourdieu, and collective emotions in contentious politics', Theory and Society, Vol. 34, pp.469-518.

Fineman, S. (1993) Emotion in Organizations, Sage, London.

Fineman, S. (2000) Emotion in Organizations, 2nd ed., Sage, London.

Finlay, L. (2002) 'Outing' the researcher: the provenance, process, and practice of reflexivity', Qualitative Health Research, Vol. 12, pp.531-545.

Fleming, P. and Sturdy, A. (2011) 'Being yourself in the electronic sweatshop: new forms of normative control', Human Relations, Vol. 64, No. 2, pp.177-200.

Foley, D.E. (2002) 'Critical ethnography: the reflexive turn', Qualitative Studies in Education, Vol. 15, No. 5, pp.469-490.

Gold, R.L. (1958) 'Roles in sociological field observations', Social Forces, Vol. 36, No. 3, pp.217-223. 
Hardy, C. Phillips, N. and Clegg, S. (2001) 'Reflexivity in organization and management theory: a study of the production of the research 'subject", Human Relations, Vol. 54, No. 5, pp.531-560.

Hertz, R. (1996) 'Introduction: ethics, reflexivity and voice', Qualitative Sociology, Vol. 19, No. 1, pp.3-7.

Hochschild, A.R. (1983) The Managed Heart: Commercialisation of Human Feeling, University of California Press, London.

Holland, R. (1999) 'Reflexivity', Human Relations, Vol. 52, No. 4, pp.519-556.

Hubbard, G., Beckett-Milburn, K. and Kemmer, D. (2001) 'Working with emotion: issues for the researcher in fieldwork and teamwork', International Journal of Social Research Methodology, Vol. 4, No. 2, pp.119-137.

Jaggar, A.M. (1989) 'Love and knowledge: emotion in feminist epistemology', Inquiry An Interdisciplinary Journal of Philosophy, Vol. 32, No. 2, pp.151-176.

James, N. (1989) 'Emotional labour: skill and work in the social regulation of feelings', Sociological Review, Vol. 37, pp.15-47.

Jarzabkowski, L. (2001) 'Emotional labour in educational research', Queensland Journal of Educational Research, Vol. 17, No. 2, pp.123-137.

Korczynski, M. (2003) 'Communities of coping: collective emotional labour in service work', Organization, Vol. 10, No. 1, pp.55-79.

Laslett, B (1990) 'Unfeeling knowledge: emotion and objectivity in the history of sociology', Sociological Forum, Vol. 5, No. 3, pp.413-433.

Leibing, A. and McLean, A. (2007) 'Learn to value your shadow!" An introduction to the margins of fieldwork', in McLean, A. and Leibing, A. (Eds.): The Shadow Side of Fieldwork Exploring the Blurred Borders between Ethnography and Life, Blackwell, Oxford.

Lumsden, K. (2009) "“Don't ask a woman to do another woman's job": Gendered interactions and the emotional ethnographer', Sociology, Vol. 43, No. 3, pp.497-513.

Lynch, M. (2000) 'Against reflexivity as an academic virtue and source of privileged knowledge', Theory, Culture and Society, Vol. 17, No. 3, pp.26-54.

Macdonald, C.L. and Sirianni, C. (Eds.) (1996) Working in the Service Society, Temple University Press, Philadelphia.

Maton, K. (2003) 'Reflexivity, relationism and research: Pierre Bourdieu and the epistemic conditions of social scientific knowledge', Space and Culture, Vol. 6, No. 1, pp.52-65.

Mauthner, N.S., Parry, O. and Backett-Milburn, K. (1998) 'The data are out there, or re they? Implication for archiving and revisiting qualitative data', Sociology, Vol. 32, No. 4, pp.733-745.

Murphy, E. and Dingwall, R. (2001) 'The ethics of ethnography', in Atkinson, P., Coffey, A., Delamont, S., Lofland, J. and Lofland, L. (Eds.): Handbook of Ethnography, Sage, London, pp.339-351.

Pillow, W. (2003) 'Confession, catharsis, or cure? Rethinking the uses of reflexivity as methodological power in qualitative research', Qualitative Studies in Education, Vol. 16, No. 2, pp.175-196.

Reger, J. (2001) 'Emotions, objectivity and voice: an analysis of a 'failed' participant observation', Women's Studies International Forum, Vol. 24, No. 5, pp.605-616.

Riach, K. (2009) 'Exploring participant-centred reflexivity in the research interview', Sociology, Vol. 43, No. 2, pp.356-370.

Russell, B. (2002) 'The talk shop and shop talk: employment and work in a call centre', Journal of Industrial Relations, Vol. 44, No. 4, pp.467-490.

Sherif, B. (2001) 'The ambiguity of boundaries in the fieldwork experience: establishing rapport and negotiating insider/outsider status', Qualitative Inquiry, Vol. 7, No. 4, pp.436-447.

Sifneos, P.E. (1973) 'The prevalence of 'alexithymic' characteristics in psychosomatic patients', Psychotherapy and Psychosomatics, Vol. 22, Nos. 2-6, pp.255-262. 
Sin, C.H (2005) 'Seeking informed consent: reflections on research practice', Sociology, Vol. 39, No. 2, pp.277-294.

Skeggs, B. (2004) 'Exchange, value and affect: Bourdieu and 'the self', in Adkins, L. and Skeggs, B. (Eds.): Feminism After Bourdieu, Blackwell, Oxford.

Sturdy, A., Grugulis, I. and Willmott, H. (2001) Customer Service Empowerment and Entrapment, Palgrave, London.

Taylor, P. and Bain, P. (1999) “"An assembly line in the head": work and employee relations in the call centre', Industrial Relations Journal, Vol. 30, No. 2, pp.101-117.

Taylor, P., Hyman, J., Mulvey, G. and Bain, P. (2002) 'Work organization, control and the experience of work in call centres', Work, Employment and Society, Vol. 16, No. 1, pp. $133-150$

Taylor, S. (1998) 'Emotional labour and the new workplace', in Thompson, P. and Warhurst, C. (Eds.): Workplaces of the Future, Macmillan, Basinstoke.

Thoits, P.A. (1989) 'The sociology of emotions', Annual Review of Sociology, Vol. 15, pp.317-342.

Willig, C. (2001) Introducing Qualitative Research in Psychology: Adventures in Theory and Method, Open University Press, Buckingham.

\section{Bibliography}

Hancock, P. and Tyler, M. (2001) Work, Postmodernism and Organization, Sage, London.

Hutchinson, S., Purcell, J. and Kinnie, N. (2000) 'Evolving high commitment management', Human Resource Management Journal, Vol. 10, No. 1, pp.63-79.

Kinnie, N., Hutchinson, S. and Purcell, J. (2000) 'Fun and surveillance': the paradox of high commitment management in call centres', International Journal of Human Resource Management, Vol. 11, No. 5, pp.964-985.

Korczynski, M. (2001) 'The contradictions of service work: call centre as customer-oriented bureaucracy', in Sturdy, A., Grugulis, I. and Willmott, H. (Eds.): Customer Service Empowerment and Entrapment, Palgrave, Basingstoke.

Lave, J. and Wenger, E. (1991) Situated Learning Legitimate Peripheral participation, Cambridge University Press, Cambridge. 